\title{
Creative Learning Methods and Open Choice of Topics Facilitate Self-Directed Learning and Motivation of Veterinary Students
}

\author{
Carola Fischer-Tenhagen, Wolfgang Heuwieser, Sebastian Arlt \\ Clinic for Animal Reproduction, Free University Berlin, Germany \\ Email: Fischer-tenhagen@fu-berlin.de
}

Received 30 June 2016; accepted 22 August 2016; published 25 August 2016

Copyright @ 2016 by authors and Scientific Research Publishing Inc.

This work is licensed under the Creative Commons Attribution International License (CC BY).

http://creativecommons.org/licenses/by/4.0/

(c) (;) Open Access

\begin{abstract}
The veterinary curriculum is predominantly characterized by lecturing large amounts of facts than by self-directed learning of the students. According to previous research on educational concepts, however, by just listening, students memorize a smaller fraction of the presented information. In addition, the ability of self-directed learning is a perquisite for lifelong acquisition up to date knowledge for veterinary practitioners. In this project 162 fourth year students attending the clinical rotation of reproduction of domestic animals were enrolled. To motivate students to engage in self-directed learning, instead of writing a clinical case report, they were allowed to choose a topic of their own interest in the field of animal reproduction. They had a free choice for the method of presentation. Their attitudes and experiences were evaluated in a questionnaire. 87.7\% of students decided to research and present a topic of their own choice instead of a clinical case report. They presented the information with a talk (44.9\%), a quiz or board game $(26.8 \%)$, a poster, video $(18.8 \%)$, or with a model $(5.1 \%)$. Evaluation of the project revealed that the time for preparation did not differ between a chosen topic and a case report. The students stated that learning success and motivation was higher when preparing or listening to presentations and colleague talks compared to writing standard case reports. Overall, motivation was high and as a side effect, the students produced valuable teaching material for following courses.
\end{abstract}

\section{Keywords}

Self-Directed Learning, Choice of Topic, Presentation to Colleagues

\section{Introduction}

Veterinary practitioners and clinicians need to engage in self-directed, lifelong learning to remain up to date

How to cite this paper: Fischer-Tenhagen, C., Heuwieser, W., \& Arlt, S. (2016). Creative Learning Methods and Open Choice of Topics Facilitate Self-Directed Learning and Motivation of Veterinary Students. Creative Education, 7, 1906-1912.

http://dx.doi.org/10.4236/ce.2016.714193 
since knowledge rapidly progresses (Blumberg, 2005; Arlt et al., 2012). Self-directed learning has been defined as the competence to employ learning activities by oneself rather than by a teacher (Blumberg, 2005). Prerequisites for this are competencies on knowledge acquisition and an adequate self-motivation (Schmidt, 2000; Straus \& Sackett, 1998).

Recent veterinary curricula are predominantly based on teaching large amounts of information (Arlt et al., 2012; Kochevar, 2006) by lectures and seminars. Advantages of these teaching methods are that they structure the facts to learn and transport much information in a short time period (Mc Lennan \& Heath, 2000). Nevertheless, students usually sit passively in lecture halls and seminar rooms and mostly write without thinking activity (Mc Lennan \& Heath, 2000) leading to superficial learning which is easily forgotten. Moreover, the consequence of providing excessive information may be that the students actually learn less (Biggs \& Tang, 2011). When learners simply try to memorize material, they may fail to really understand it (Blumberg, 2005; Mc Lennan \& Heath, 2000). According to Blooms Taxonomy (Bloom, 1956) the lowest cognitive level is the acquisition of knowledge. This level is defined as remembering or retrieving previously learned material. Learning objectives at this level often include defining key terms, listing steps in a process, or repeating something heard or seen. When lecturers implement this level, learners may not have the chance to think critically enough about what they are learning and to apply the learned information (Munzenmaier \& Rubin, 2013). Döring (1999) proclaimed that thorough learning included not only listening and memorizing information, but also reproducing newly learned knowledge first in a safe learning environment and then in the real world. If students understand information and the medical context, they are more likely to remember the facts. Especially modifying information and teaching others leads to a remarkable high retention rate of knowledge (Bale, 2006).

Veterinary practice often requires critical and flexible thinking and problem solving when uncommon cases and circumstances are encountered (Lane, 2008). Dynamic cognitive processes of critical thinking and problem solving, however, are hardly taught in veterinary curricula (Kochevar \& Fajt, 2006). In self-directed learning, students are expected to learn from the world's knowledge and accumulated expertise by virtue of their own study and research, just as real practitioners do (Barrows, 1996). In that regard, they need to determine which information they need and how to find and evaluate this information. Finally, they need to learn to decide whether the information is adequate and sound for the implementation into practice.

Students also need to learn skills in communicating with patient owners. Presenting facts about cases, diseases and treatment options are necessary to obtain an informed consent by the owner. Therefore, it may be advantageous to train how to convincingly inform others about medical issues with little technical terms and in a way that clientele with no or little medical background are able to follow. These skills, however, are rarely trained in veterinary education.

Results of projects that aim to stimulate veterinary students to play a more active role in teaching medical subjects have hardly been published.

The objective of the project was to involve students in the teaching process by developing innovative teaching materials. Specifically, we set out to test two hypotheses:

1) Students are more highly motivated if they are allowed to choose the topic and method of presentation.

2) Veterinary students spend more time preparing a topic of their own choice than on working on a case report of an assigned clinical patient.

\section{Material and Methods}

Between November 2012 and August 2013 a total of 162 veterinary medicine students from Free University in Berlin attended a clinical rotation at the Clinic for Animal Reproduction. The students were in their fifth year and participated in the clinical rotation in a group of eight to ten students for two weeks.

On the first day the project was introduced to the students. As an alternative to the clinical examination of a patient of the Clinic of Animal Reproduction and writing a case report the students had the opportunity to choose a topic of their own interest and to present it in any creative way they wanted. Each student was obliged to write a case report or to prepare an alternative presentation about a topic from the field of animal reproduction. There were no constraints regarding the mode of presentation. As examples we suggested talks, poems, songs, cartoons, models, puzzles, quizzes, games, videos. The only requirement was that the results of the presentation should lead to an explicit learning success for the student and his or her peers and that it should not exceed ten minutes. 
The presentations were scheduled individually in agreement with the students. Few presentations were held at the end of the first week. Most presentations were given during the second week. Students were offered the possibility for reimbursement of expenses for material such as colored paper, card board, modeling clay, or other arts and crafts material. No student, however, asked for reimbursement.

After the last presentation of the group a questionnaire was distributed for evaluation of the project. Students could voluntarily and anonymously fill in the questionnaire. It contained questions about whether a clinical case or an alternative topic was chosen and with which method the results were presented. In addition, we asked for a brief statement on the motivation for the above stated choices. It was possible to describe more than one motivation. Finally, we asked the students to estimate the time spent to prepare the presentation. In a second part the questionnaire presented statements about the project, and the respondents were asked to indicate the level to which they agreed with the statements on a five-point Likert scale (see Figure 1).

\section{Statistics}

Statistical analyses were performed with IBM SPSS Statistics for Windows software (version 20.0; IBM Deutschland $\mathrm{GmbH}$, Ehningen, Germany). The normal distribution of the type of topic and preparation time was tested by calculating a quantile-quantile (Q-Q) plot and performing a Shapiro-Wilk test. According to the Shapiro-Wilk test data were not normally distributed $(p<0.05)$. Difference of preparation time for topic of free choice or case report, were tested with Wilcoxon-Mann-Whitney test. The difference in attitude of students toward case report, talks and presentations were tested with Wilcoxon-Rank analysis.

\section{Results}

In total, 138 students filled in the questionnaire. The remaining students were on farm visits or ill on the last day of the clinical rotation. Out of the 138 students, $84.1 \%$ were female and average age was $26.3 \pm 3.6$ years. 121 $(87.7 \%)$ students chose a topic of free choice, whereas only $17(12.3 \%)$ decided for a clinical case report. The majority of students $(n=62,44.9 \%)$ decided to present their topic in a talk with or without slides. A total of 37 students $(26.8 \%)$ created a quiz or board game, $26(18.8 \%)$ presented a poster, cartoon or movie and 7 participants $(5.1 \%)$ built a model. An example of a model displays in Figure 2.

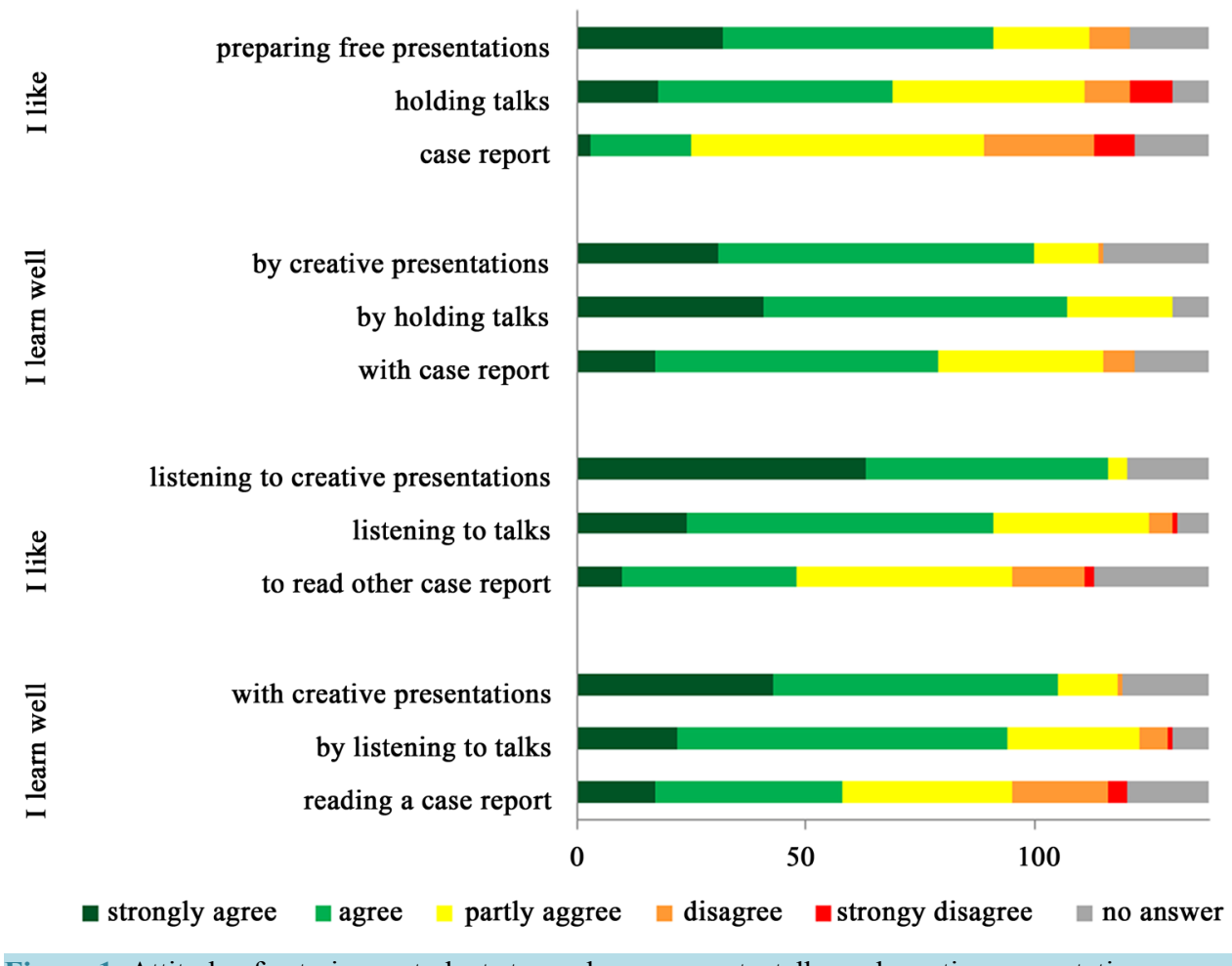

Figure 1. Attitude of veterinary students towards case reports, talks and creative presentations. 


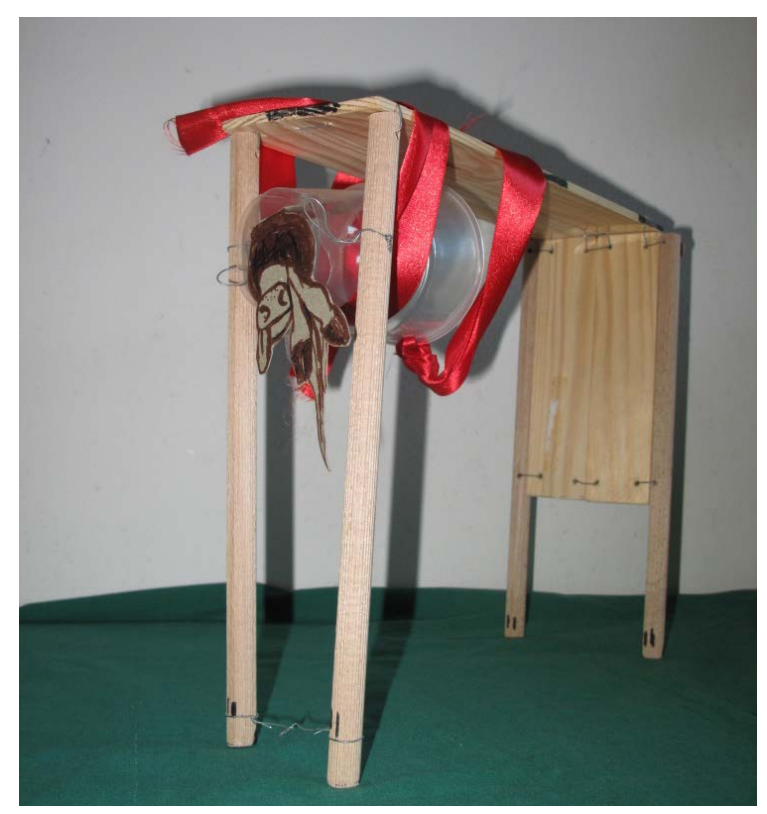

Figure 2. Model designed by students to demonstrate the position of uterine ligaments in case of uterine torsion in the cow.

When describing their motivation to choose a topic of free choice the most frequent reason $(n=37)$ given was personal interest. The topic was considered to be relevant for the exams $(n=17)$, the students believed it would be fun and that they learned more effectively from this $(n=15)$, it was not included in the normal curriculum $(\mathrm{n}=14)$, it was useful repetition of a topic or they were motivated by personal experience from practice $(\mathrm{n}=$ $10)$.

Students spent 6.2 hours \pm 4.0 for the preparation of a clinical case report. Preparing an alternative topic took 8.0 hours \pm 6.9 . Therefore, for preparing an alternative topic additional 1.8 hours were necessary $(p=0.28)$.

Other results of the evaluation are given in Figure 2. Students liked giving talks $(50.0 \%$ agreed or strongly agreed) or preparing a creative presentation (65.9\% agreed or strongly agreed) significantly better than preparing a case report $(18.1 \%$ agreed or strongly agreed, $p=0.01)$. They felt they learned most effectively by giving a talk followed by delivering a creative presentation form and a case report $(77.5 \%, 72.5 \%$ and $57.2 \%$ agreed or strongly agreed, respectively; $p<0.01$ ). As a listener, students favored alternative presentation forms of their fellow students most $(84.1 \%$ agree or strongly agree; $p<0.01)$, before listening to a talk and then reading a case report $(65.9 \%$ and $84.6 \%$ agreed or strongly agree, $p<0.01)$. Regarding the effectiveness of learning from peers students felt that creative presentation forms are more effective $(76.1 \%$ agreed or strongly agreed $p<0.01)$ than listening to a talk $(71.2 \%$ agreed or strongly agreed, $p<0.01)$ or reading a case report $(42.1 \%$ agreed or strongly agreed, $\mathrm{p}>0.01)$.

In an open text question students were ask to describe their attitude towards the choice of presentation forms. The answers included statements like "I like doing creative things" $(n=13)$, "interactive presentation enhances learning effect" $(\mathrm{n}=12)$, "time was too short for developing creative material" $(\mathrm{n}=7)$, "a talk is a good way for presentation" ( $(n=10)$, "I am a visual learning type" $(n=4)$, "good alternative to case reports" $(n=3)$.

\section{Discussion}

In this project $80 \%$ of students took the opportunity to choose a topic of their own choice and to present it to their peers. In the survey, students confirmed that most of them preferred a creative presentation form or holding a talk to preparing a case report. The possibilities to choose topics of own interest seems to enhance intrinsic motivation of the students to deal with the information. In addition, results suggest that students are motivated to involve themselves in the teaching process. Students commented that they considered their topics to be important and that they had difficulties to understand and learn them in detail without an adequate approach and suffi- 
cient repetition. Similarly, Parkinson et al. (2006) stated that student's motivation is high when they are studying subjects that are seen as relevant to clinical practice. In our case also relevance for the outstanding exams may also have played a role.

In this project students had to take responsibility for their own learning process. They had to identify what they needed to know to better understand and manage the topic on which they were working and to determine where they will get information (Barrows, 1996). The students stated that they learned more by preparing and giving a talk than by working on a case report with a systematic outline. These skills are essential especially if new information or data are needed in veterinary practice.

The possibility to choose a topic of their own choice also allowed each student to personalize learning interests, to concentrate on areas of limited knowledge or understanding, and to pursue areas of interest (Barrows, 1996). This is reflected in the choice of some special areas that were not considered in our recent curriculum such as sexing of reptiles, aspects of the reproduction of naked mole rats or salmons. One might argue that this information is not directly relevant for veterinarians as a first day competence. But most of these topics were chosen on the basis of experience during work practices in veterinary clinics and hence found to be relevant. From a didactic perspective these topics lead to the same learning processes regarding searching information and teaching selected aspects to the fellow students. In addition, the students mostly presented their information in an enthusiastic way and such motivated their peers to learn about these side issues.

Many students stated that preparing a creative presentation was fun. Many wanted to facilitate interaction between their peers and therefore prepared games or quizzes. Their peers appreciated their efforts and enjoyed participating in the alternative presentation forms most. Some students found rhymes to be helpful to remember difficult facts.

The creative development of teaching material lead to a compilation of different posters, quizzes, board games and models (Figure 2). The topics were presented in a highly motivated atmosphere and the participants in many cases complimented their peers for their enthusiastic and high quality work. These are now available for subsequent groups of students attending the clinical rotation for self-directed studies. The material is stored in a dry lab room that also is used by the students for breaks and self-directed learning. During the clinical rotation two afternoons are dedicated for the preparation of case reports, presentations, and self-directed learning.

It has to be pointed out that in several cases the students developed interesting innovative student-centered approaches for talks or demonstration material to present and explain knowledge. Utilizing this creative potential may be used for the development of better supporting explanation approaches and educational material to be used in veterinary education. Part of educational materials developed is student-centered and may be better tied in with the actual knowledge base of the peers.

Preparation time did not differ between a case report and a topic chosen by the students.

Due to the wide heterogeneity of topics and presentation methods a formal and objective evaluation of the learning success of the chosen topics compared to case reports was not possible and also not the scope of our study. Nevertheless, according to the learning pyramid by Bale (2006) teaching others leads to a remarkable higher retention rate of knowledge than writing. Incidentally, the lowest retention rate is obtained by visiting lectures. According to Wood (2013) highest levels of learning and understanding come from evaluation and synthesis. In our project the students had to evaluate which information was relevant when preparing their presentations. Synthesis was particularly involved when information was changed from one form to another e.g. from research papers and textbooks into models or board games. Such an approach allows a deeper understanding of the topic and a higher retention of the knowledge Wood (2013).

To what extent these levels of learning were really achieved in regard to our project remains open. However, the students stated that they felt they have learned most by preparing the creative presentations.

For the creation of educational material information retrieved has to be transferred and modified into a different format relating to the teaching context. This means that the students intensively have to revise and adapt information on their topic what presumably leads to a high learning success ${ }^{15}$. In most cases the development of the teaching material was based on a comprehensive literature search and editing of the information so that the lecturers had little to correct or to add. Some developed teaching material, nevertheless, contained mistakes or were incomplete or outdated in regard to the presented topic. In these cases the lecturers or peers corrected the information. In some cases this lead to interesting discussion that represent a specific learning objective on its own.

In peer assisted learning outdated, misleading or simply wrong information may be presented. This could be 
minimized by a previous training in finding, retrieving and critical appraisal of current literature. Due to time limitations students may prefer to use readily available sources such as textbooks or the internet. Therefore, we recommend that a lecturer should always attend the presentations and critically evaluate and if necessary correct information. It is noteworthy, that also the peers noticed mistakes and thus an intervention of the lecturer was not necessary in many cases. This approach of self-directed learning with discussing, comparing, reviewing, and debating the information (Barrows, 1996) may lead to a good learning success for all participants. In some cases, also the lecturers learned new knowledge or different considerations. Further research is warranted to formally test the hypothesis that the learning success is higher if students can choose topics of personal interest, study them intensively and present them to their peers.

\section{Conclusion}

Our project showed that students were highly motivated to create own teaching materials. They experienced the value and gain of knowledge by self-directed learning. Teaching via lectures and seminars may be complemented with creative and self-directed learning.

Nevertheless, creative work was not favored by all students. In addition, the development of creative material may be difficult for some students and cause stress (Mc Lean \& Gibbs, 2009). So alternatives like preparing talks or writing case reports could be offered to meet the needs of all learning types. Some students complained that the given time was too short for creative development of teaching material. In average, students had 3 to 4 afternoons or a weekend to prepare for their presentation. Maybe more time would have improved the results. When conducting similar projects we suggest scheduling at least two weeks for preparing the case reports and presentations.

\section{References}

Arlt, S. P., Haimerl, P., \& Heuwieser, W. (2012). Training Evidence-Based Veterinary Medicine by Collaborative Development of Critically Appraised Topics. Journal of Veterinary Medical Education, 39, 111-118. http://dx.doi.org/10.3138/jvme.1111.112R

Bale, V. (2006). How My Practice of Using Manipulatives in Teaching Multiplying and Dividing Fractions Influences the Student's Conceptual Understanding of These Operations. Department of Teaching and Learning Principles, Orlando, FL: B.S. University of Central Florida.

Barrows, H. S. (1996). Problem-Based Learning in Medicine and Beyond: A Brief Overview. New Directions for Teaching and Learning, 1996, 3-12. http://dx.doi.org/10.1002/t1.37219966804

Biggs, J., \& Tang, C. (2011). Teaching for Quality Learning at University. Maidenhead, UK: Open University Press.

Bloom, B. S., College, C., \& Examiners, U. (1956). Taxonomy of Educational Objectives. New York: David McKay.

Blumberg, P. (2005). Why Self-Directed Learning Is Not Learned and Practiced in Veterinary Education. Journal of Veterinary Medical Education, 52, 291-295. http://dx.doi.org/10.3138/jvme.32.3.290

Döring, K. W., \& Ritter-Mamczek, B. (1999). Lehren und Trainieren in der Weiterbildung. Weiterbildung: Dt. StudienVerlag.

Kochevar, D., \& Fajt, V. (2006). Evidence-Based Decision Making in Small Animal Therapeutics. Veterinary Clinics of North America: Small Animal Practice, 36, 943-959. http://dx.doi.org/10.1016/j.cvsm.2006.06.001

Lane, E. A. (2008). Problem-Based Learning in Veterinary Education. Journal of Veterinary Medical Education, 35, 631636. http://dx.doi.org/10.3138/jvme.35.4.631

Mc Lean, M., \& Gibbs, T. J. (2009). Lerner-Centered Medical Education: Improved Learning or Increased Stress? Education for Health, 22, 287.

Mc Lennan, M. W., \& Heath, T. J. (2000). The Role of Lectures in Veterinary Education. Australian Veterinary Journal, 78, 702-709. http://dx.doi.org/10.1111/j.1751-0813.2000.tb10412.x

Munzenmaier, C., \& Rubin, N. (2013). Bloom's Taxonomy: What's Old Is New Again. The Learning Guild Research, Retrieved 15 May 2014.

Parkinson, T. J., Gilling, M., \& Suddaby, G. T. (2006). Workload, Study Methods, and Motivation of Students within a BVSc Program. Journal of Veterinary Medical Education, 33, 253-265. http://dx.doi.org/10.3138/jvme.33.2.253

Schmidt, H. G. (2000). Assumptions Underlying Self-Directed Learning May Be False. Medical Education, 34, $243-247$. http://dx.doi.org/10.1046/j.1365-2923.2000.0656a.x 
Straus, S. E., \& Sackett, D. L. (1998). Using Research Findings in Clinical Practice. British Medical Journal, 317, 339-342. http://dx.doi.org/10.1136/bmj.317.7154.339

Wood, E. (2013). Problem-Based Learning: Exploiting Knowledge of How People Learn to Promote Effective Learning.

\section{Submit or recommend next manuscript to SCIRP and we will provide best service for you:}

Accepting pre-submission inquiries through Email, Facebook, LinkedIn, Twitter, etc.

A wide selection of journals (inclusive of 9 subjects, more than 200 journals)

Providing 24-hour high-quality service

User-friendly online submission system

Fair and swift peer-review system

Efficient typesetting and proofreading procedure

Display of the result of downloads and visits, as well as the number of cited articles

Maximum dissemination of your research work

Submit your manuscript at: http://papersubmission.scirp.org/ 